\section{Estudo \\ Ecidebate}

em CAStão

Plamejamento
Revista Estudo \& Debate, Lajeado, v. 25, n. 3, 2018. ISSN 1983-036X

DOI: http://dx.doi.org/10.22410/issn.1983-036X.v25i3a2018.1946

\title{
DINÂMICA REGIONAL DO EMPREGO VERDE NO BRASIL ENTRE 2007 E 2015
}

\author{
Stela Luiza de Mattos Ansanelli², Luiz Henrique Bispo Santos ${ }^{3}$
}

\begin{abstract}
Resumo: Empregos verdes são postos de trabalho criados a partir de atividades econômicas que, direta ou indiretamente, contribuem para a melhoria da qualidade ambiental ou mitigam efeitos danosos sobre ela. Entre 2007 e 2015, estes empregos cresceram 30,23\% em todo o país. No entanto, como o Brasil possui dimensões continentais, não há evidências da dinâmica dos empregos verdes em termos regionais. $\mathrm{O}$ presente trabalho coopera com as investigaçóes recentes sobre o tema, explorando, a partir do modelo shift-share (ou método diferencial-estrutural), a dinâmica destes empregos nas regiôes do Brasil. Também, busca-se aqui uma avaliação sobre o perfil destes empregos concernente à escolaridade e remuneraçáo dos trabalhadores. As evidências apontam que a principal influência sobre a dinâmica dos empregos verdes no país é o efeito nacional, bem como há uma tendência de desconcentração regional dessa tipologia de emprego, uma vez que regióes economicamente consideradas periféricas são as que apresentam as maiores taxas de crescimento no período analisado. Similarmente, verifica-se a capacidade que esta parcela do nosso mercado de trabalho tem de inclusão social por apresentar os melhores resultados sobre escolaridade e remuneraçáo.
\end{abstract}

Palavras-chave: Mercado de trabalho. Sustentabilidade. Regionalismo. Emprego Verde. Shift-Share.

\section{REGIONAL DYNAMICS OF GREEN JOBS IN BRAZIL BETWEEN 2007 AND 2015}

\begin{abstract}
Green jobs are work positions created from economic activities that direct or indirectly contribute to improve environmental quality or mitigate harmful effects on such quality. Between 2007 and 2015, these jobs have increased $30.23 \%$ through the whole country. However, as Brazil is a continental-size country, there is no evidence of green jobs' dynamics in regional terms. This paper cooperates with current researches on the subject by exploring, from the shift-share model (or structural-differential method), the dynamics of these jobs in Brazilian regions. In addition, one also aims here to assess the profile of these jobs in relation to educational level and remuneration. The evidence points out that the main influence on the dynamics of green jobs in
\end{abstract}

1 Um ensaio preliminar deste artigo, referente a outro período e sem a revisão da literatura, foi apresentado no $5^{\circ}$ Congresso Internacional de Tecnologia para o Meio Ambiente, realizado entre 5 e 7 de abril de 2016 em Bento Gonçalves - RS.

2 Professora Doutora do Departamento de Economia da UNESP - Universidade Estadual Paulista (stelansa@hotmail.com).

3 Graduado em Economia pela UNESP - Universidade Estadual Paulista (henrique.petrelli@hotmail.com). 
Brazil is the national effect, as well as the existence of an inclination to regional decentralization of this type of employment, since the regions economically deemed as fringe are those showing the highest growth rates for the period analyzed. Similarly, one checks the capacity of social inclusion of this share of our job market, as it presents the best results about educational level and remuneration.

Keywords: Job market. Sustainability. Regionalism. Green Jobs. Shift-Share.

\section{Introduçáo}

A ascensão da Economia Verde fornece oportunidades de ganhos triplos: proteção ambiental e crescimento de postos de trabalhos vinculados às atividades de preservação ambiental. A Economia Verde, conforme UNEP (2008), significa uma economia com crescente bem-estar social e capital humano com queda significativa de riscos ambientais e ecológicos no sentido de alcançar o desenvolvimento sustentável e a redução da pobreza. Esse conceito engloba práticas econômicas ambientalmente adequadas e socialmente equitativas.

Empregos verdes sáo postos de trabalho gerados a partir de atividades associadas à conservação ambiental e se tornaram o símbolo de uma economia fundamentada em novos padróes de consumo e produçáo, que exigem um redirecionamento para as atividades produtivas que respeitem a restrição imposta pelo meio ambiente.

Segundo a Organização Internacional do Trabalho (2009b), a análise do emprego verde se divide em dois grupos: o das atividades que contribuem para a redução do efeito estufa e para a preservação da qualidade ambiental (produção, manejo, geração e distribuição de energia, saneamento, transporte coletivo, telecomunicaçôes, entre outras) e o das atividades extrativas que dependem da qualidade ambiental (extração mineral e indústria de base, construção, agricultura, pecuária, pesca, entre outras).

Observa-se que emprego verde, portanto, pode estar alocado em quaisquer atividades, como na agricultura, indústria, construção civil, instalação e manutenção, bem como em atividades científicas, técnicas, administrativas e de serviços que tenham, direta ou indiretamente, impactos ambientais positivos (OIT, 2009b).

É preciso observar que esse conceito está vinculado ao de emprego decente, entendido aqui como aquele que garante proteção social e jurídica ao trabalhador. A peculiaridade da definição da OIT é que essa não se relaciona a cargos ou a perfis profissionais específicos, mas sim a postos de trabalho em setores econômicos que possuem impactos ambientais positivos concretos (OIT, 2009b).

Um crescimento mais amigável ao meio ambiente tende a criar novos postos de trabalho que são necessários para realocar a força de trabalho que perderá seus empregos com a destruição de atividades poluentes. Somente com a transição para uma matriz energética mais sustentável, o mundo poderia ganhar pelo menos 20 milhôes de empregos verdes até 2030 (OCDE, 2011).

No Brasil, a evoluçáo das atividades econômicas se deu de forma periférica, bastante dependente do setor externo e altamente predatória do ponto de vista ambiental (BARCELLOS, 2001). Entretanto, nos últimos anos, as atividades ambientais ganharam espaço em nossa economia, promovendo a criação de ocupaçóes ambientalmente amigáveis, pois representaram 6,73\% do emprego formal no Brasil em 2008 (OIT, 2009b). 
Como o Brasil é um país continental com uma ampla diversidade em termos de atividades econômicas e características sociais e ambientais, o objetivo deste trabalho é investigar a dinâmica regional e a qualidade dos empregos verdes no Brasil entre 2007 e 2015. Argumenta-se, neste artigo, que as atividades verdes, conforme classificação da OIT (2009b) tem o potencial de promover desconcentração regional e inclusão social.

Uma pesquisa com essa dimensão é importante por atualizar e aprofundar o estudo da OIT (2009b) no que diz respeito ao Brasil, bem como por fornecer elementos para discussão dos fatores determinantes e o impacto das atividades verdes no país.

Este trabalho está dividido em três partes, além desta introdução. $\mathrm{Na}$ segunda, busca-se um levantamento da literatura existente sobre o tema "empregos e economia verde"; em seguida, na seção três, apresentam-se a confecção do modelo utilizado aqui e os indicadores sociais; na seção quatro, são discutidos resultados obtidos e, por fim, são feitas as consideraçóes finais.

\section{Mercado de trabalho e Economia Verde: referencial da literatura}

O século XXI trouxe dois grandes desafios para as economias mundiais. O primeiro trata da necessidade de desenvolvimento econômico, que deve ser entendido a partir da urgência de inclusão social daqueles que permaneceram à margem do crescimento destas economias. E o segundo refere-se à consecuçâo da sustentabilidade, que consistiria na produção da riqueza material com impactos nulos ou mínimos sobre o meio ambiente.

Neste contexto, a transição para uma Economia Verde representa uma transformação economicamente viável, socialmente inclusiva e ambientalmente sustentável (UNEP, 2011). Dessa maneira, os mercados seriam adaptados para respeitar os limites impostos pela natureza, como uma resposta a esses desafios.

Essa transformação seria benéfica especificamente ao mercado de trabalho, na medida em que gerasse empregos com capacidade de redução das desigualdades, manutenção da qualidade ambiental e promoção da geração de renda. É preciso compreender as definiçóes que delimitam o assunto, bem como fazer uma análise prévia sobre a conjuntura brasileira.

Da intersecção entre sustentabilidade e mercado de trabalho surge a Iniciativa Empregos Verdes ${ }^{4}$, um consórcio internacional e multi-institucional que pretende investigar a questão trabalhista nessa transição. Segundo o relatório produzido pela Organização Internacional do Trabalho (OIT), empregos verdes são postos de trabalho oriundos de atividades econômicas que contribuem diretamente para a preservação da qualidade ambiental ou concorrem para mitigar efeitos danosos sobre ela (OIT, 2009b).

4 Uma parceria entre Programa das Naçôes Unidas para o Meio Ambiente (PNUMA), Organização Internacional do Trabalho (OIT), Organização Internacional de Empregadores (OIE) e Confederação Sindical Internacional (CSI) foi formada em 2007 com o objetivo de estudar as relaçóes entre sustentabilidade e mercado de trabalho e orientar políticas econômicas voltadas para o tema. 
A condição de existência para estes empregos seria o trabalho decente, ou seja, um trabalho que assegure as condições de proteção social, com carteira assinada, assistência jurídica, segurança laboral e condiçóes dignas para o trabalhador e sua família (OIT, 2009b).

Ainda, segundo o relatório produzido pela OIT, foi realizada uma opção metodológica para se mapear e quantificar estes tipos de emprego pelo Brasil. A proposta apresentada é avaliar os empregos gerados a partir de atividades econômicas de acordo com seus impactos sobre o meio ambiente. Conforme o produto ou serviço final de uma atividade econômica contribui para a preservaçáo do meio natural, os empregos gerados no processo são considerados verdes.

São seis segmentos de atividades econômicas classificadas como verdes: produção e manejo florestal; geração e distribuição de energia renovável; saneamento, gestão de resíduos e riscos ambientais; manutenção, reparação e recuperação de produtos e materiais; transporte coletivo e alternativo ao rodoviário e aeroviário; e telecomunicações e teleatendimento, conforme Anexo (OIT, 2009b).

De acordo com esse estudo da OIT, que investigou apenas o ano de 2008, foram gerados no Brasil mais de 2.600 .000 postos de trabalho em atividades verdes, o que representou $6,73 \%$ de todo o emprego formal no país.

Neste trabalho, utiliza-se a classificação sugerida pela OIT, pois é o único estudo realizado para o Brasil com disponibilidade de dados e indicadores que atendem à definição de emprego decente.

\subsection{O emprego na transiçáo para Economia Verde}

Esta seção analisa a literatura sobre a transição para economia verde e como o mercado de trabalho por ser afetado por ela. Percebe-se que algumas questóes sáo sensíveis nesse contexto, como salários e qualificação do capital humano. Estas duas variáveis são centrais em qualquer debate sobre políticas de ganhos triplos objetivados pelos defensores do esverdeamento da economia.

No estudo sobre o potencial de crescimento da economia verde, Young (2011) questiona o que gera maior crescimento econômico: a expansão de atividades intensivas em recursos naturais e, portanto, nocivas ao meio ambiente, ou daquelas baseadas em manufaturas. E, dentro do setor manufatureiro, foi observado que o maior crescimento advém das indústrias mais poluidoras (sujas) ou menos intensivas em poluiçẫo (verdes).

O trabalho de Young (2011) baseia-se no modelo insumo-produto, cujas variáveis são projetadas para o futuro e são avaliadas a partir da hipótese de aumento da demanda. Como resultado, observou-se que a expansão no setor primário tende a gerar maior número de empregos, entretanto empregos de pior qualidade e menores salários. Dentro do setor manufatureiro, a indústria que apresenta maior nível de emprego é a que polui menos (o setor verde), a que oferece os maiores salários.

Young (2011) questiona a oposição entre crescimento econômico e preservaçáo ambiental. Segundo o autor, é possível que a expansão de atividades de baixo impacto 
ambiental tragam melhores resultados para a geração de emprego e renda, em comparação com o modelo atual (agroexportador).

A partir de outros métodos, Ansanelli e Santos (2016) estudaram o volume de emprego gerado entre 2007 e 2014 em diversos setores, bem como sua escolaridade e remuneração. Os autores analisaram quatro subdivisões do mercado de trabalho brasileiro: o setor primário, intensivo em recursos naturais; a indústria limpa, de menor impacto negativo sobre o meio ambiente; a indústria ambientalmente sensível, altamente emissora de poluição, também chamada de indústria suja; e a indústria verde, diretamente relacionada à preservação ambiental. Observou-se que há uma concentração do mercado de trabalho em atividades que prejudicam o meio ambiente, entretanto, o crescimento do volume de emprego é maior na indústria verde, onde estão os trabalhadores com a maior qualificação. Os maiores salários, por outro lado, estão na indústria ambientalmente sensível e limpa, respectivamente.

Assim, há um estudo apontando que, no passado recente, as maiores remuneraçóes estavam em setores ambientalmente nocivos e outro sugerindo que, no futuro, pode-se fazer a transição na economia de modo a obter ganhos triplos (econômico, social e ambiental).

Neste ínterim, uma possibilidade seria usar a crise econômica que afetou o mundo a partir de 2008 como uma oportunidade para alcançarmos o potencial da economia verde no Brasil. Em momentos como esses, práticas danosas da economia são revistas, os governos estão mais dispostos a intervir no mercado e as empresas buscam caminhos para saírem ilesas. Os empregos verdes poderiam se beneficiar deste panorama. Assim, conforme OIT (2009 a, p. 7):

Os "empregos verdes" são crucialmente importantes para superar a crise econômica. Constituem uma alternativa possível e eficaz para reativar as economias e podem contribuir para criar rapidamente uma grande quantidade de empregos. Isto também é válido para os grandes investimentos necessários para adaptar-se à mudança climática. Se forem investidos sabiamente, os recursos para superar a crise econômica poderiam deixar como legado uma infraestrutura de energia eficiente, ecossistemas recuperados, fontes de energia renovável, e empresas e ambientes de trabalho mais adaptados à mudança climática. Além disso, poderiam assentar as bases para um futuro econômico que seja mais favorável ao meio ambiente, economicamente produtivo e socialmente sustentável.

A promoção dos empregos verdes por meio da crise se daria mediante a adoção de estratégias e programas que concorram para este fim. Como exemplo de sucesso, os países da Europa têm investido em açóes que visam o desenvolvimento da educação e o treinamento de habilidades que profissionalizem a oferta da força de trabalho que o esverdeamento da economia demanda (EEO, 2013).

Mudanças sobre o sistema tributário de modo a favorecer as atividades verdes e aumentar a taxação de atividades sujas também são uma estratégia utilizada por alguns países europeus. Podem-se citar outros exemplos, tais como, subsídios para pesquisa e desenvolvimento atrelado à disseminação de tecnologias verdes, fomento do uso de energias renováveis e aumento da eficiência energética, bem como debates públicos sobre causas 
ambientais com vistas à ampliação da pressão social sobre a transição da economia verde (EEO, 2013).

Uma avaliação da literatura sobre o tema traz à tona algumas limitações que o Brasil precisa enfrentar para ampliar o número de empregos verdes. Uma primeira diz respeito à informalidade. Alguns empregos que contribuem para a sustentabilidade não podem ser considerados verdes, pois não oferecem proteção social ao trabalhador (por se tratar de emprego informal). Esse é o caso das cooperativas de reciclagem (OIT, 2009b).

Outra dificuldade a ser superada é a lacuna da capacitação. A transição para a Economia Verde exige profissionais mais preparados para o novo perfil do mercado de trabalho que virá com essa transição. É necessária uma adaptação no sistema educacional que prepare a população para os novos empregos que serão gerados e para aqueles que precisarão de requalificação (KON; SUGAHARA, 2012).

A transição para uma Economia Verde enfatiza o papel do capital humano, pois além de garantir melhores salários, ele está diretamente ligado à ocorrência de trabalho decente e possibilita que a implantação de empregos verdes diminua o "impacto ambiental das empresas, contribua para a diminuição da necessidade de energia e matérias-primas, assim como evite a deterioração e degradação de recursos naturais" (KON; SUGAHARA, 2012, p.97).

Um cuidado adicional que se deve ter é sobre a possibilidade de geração de desemprego decorrente do processo de esverdeamento da economia. Como apontam Ansanelli e Santos (2016), em termos brutos, a indústria ambientalmente sensível ainda é o setor que mais emprega. Desse modo, a transição deveria ser pensada e planejada para que a indústria verde absorva os empregos que estão sendo destruídos no processo de redução da indústria suja na economia.

Também é preciso enfatizar o papel do interesse empresarial nessa transformação. Com a ascensão do paradigma verde, surge uma demanda com consciência ecológica. As primeiras empresas que se adaptarem para atender a este novo perfil de consumidor poderão ocupar nichos de mercado ainda não explorados (OIT, 2008).

Entretanto, a maior dificuldade a ser transposta diz respeito à determinação política. Mazzucato (2014) advoga que somente um Estado empreendedor poderia guiar uma revolução industrial verde. Segundo a autora, apenas o Estado tem condiçóes de garantir crédito paciente (crédito de longuíssimo prazo que aceita o enorme risco envolvido na transação) para o desenvolvimento de inovaçóes sustentáveis, bem como, somente o Estado poderia desenvolver pesquisas nacionais para a consecução da sustentabilidade.

A tese de liderança do Estado para uma revolução verde é reforçada pelo Programa das Naçóes Unidas para o Meio ambiente (PNUMA). A agenda pública deveria incorporar objetivos que visassem o esverdeamento da economia, incentivando setores estratégicos de ampliação das atividades verdes e reduzindo dispêndio público em áreas que causam depleção de capital natural (UNEP, 2011).

A superação das limitaçóes que impedem a transição para a Economia Verde, listadas até aqui, requer um amplo planejamento estatal com envolvimento de todos os setores da sociedade civil. 


\subsection{Aspectos regionais das atividades verdes no Brasil}

Nesta seçáo, busca-se apresentar um panorama das atividades verdes em nível regional. No Brasil, é na regiāo Nordeste onde se concentram as atividades envolvendo a geraçáo de energias renováveis. A produçáo de energias renováveis localiza-se nesta regiáo devido às vantagens naturais que ela possui, tais como alta incidência de luz solar necessária para a captação nos painéis solares e a velocidade do vento que vem do oceano Atlântico em direção ao território nordestino, fazendo dele um ponto estratégico para a instalação de parques de energia eólica e solar (TOLMASQUIM, 2016).

A Regiáo Norte abriga grande parte das hidrelétricas do país, que são consideradas fontes de energia renovável, apesar de gerarem impactos socioambientais negativos como perda da biodiversidade e remoção das populaçôes de áreas alagadas. São consideradas fontes renováveis se comparadas com os meios alternativos poluentes, petróleo e gás essencialmente. Assim como a Região Nordeste, o Norte do nosso país possui vantagens naturais e abundância de recursos para exploração de energia sustentável (TOLMASQUIM, 2016).

A regiāo Centro-Oeste, historicamente considerada atrasada em relação ao restante do país, é a regiáo brasileira que apresenta o melhor desempenho no tratamento de água e esgoto, bem como na implementaçáo de políticas ligadas ao saneamento básico. Para a OIT (2009b), saneamento é um dos segmentos econômicos relacionados à geraçáo de empregos verdes. Em 2015, segundo o Instituto Trata Brasil, 50,22\% de todo o esgoto da região Centro-Oeste é tratado, o maior índice entre as regióes brasileiras. Na esfera nacional, apenas $42,67 \%$ do esgoto é tratado (INSTITUTO TRATA BRASIL, 2015).

A Regiáo Sudeste concentra a maior parte dos empregos verdes gerados no Brasil entre 2007 e 2015. Isso se deve ao grande peso que atividades econômicas relacionadas à infraestrutura e aos meios de transportes têm na consecução para uma economia verde (OIT, 2009b). Na regiāo mais desenvolvida e populosa do país, essas atividades se ampliaram de modo a absorver um grande número de trabalhadores, demonstrando a importância do desenvolvimento da infraestrutura nacional para a geração de mais postos de trabalho sustentáveis.

A Regiáo Sul apresenta os piores resultados em termos de indicadores de sustentabilidade. Um estudo sobre a construção de um Indicador de Desenvolvimento Regional Sustentável (IDRS) 5 , que considera variáveis sociais, econômicas e ambientais para a elaboraçáo de um indicador único, concluiu que na regiâo Sul, no ano 2000, apenas $0,25 \%$ do total de municípios podia ser classificado como em estágio avançado, ou seja,

5 Esse indicador foi elaborado por Bianco et al (2016) com base no Índice de Desenvolvimento Regional (IDR) desenvolvido por Gualda (1995; 2003); Ferrera de Lima et al. (2011); Rodrigues e Ferrera de Lima (2013) e a partir de dados do Instituto Brasileiro de Geografia e Estatística (IBGE), Instituto de Pesquisa Econômica Aplicada (IPEADATA), Instituto Paranaense de Desenvolvimento Econômico e Social (IPARDES), Programa das Naçôes Unidas para o Desenvolvimento (PNUD) e Relação Anual de Informaçôes Sociais (RAIS). Se IDRS $\geq 0,50$, o desenvolvimento regional sustentável é considerado avançado; se $0,10 \leq$ IDRS $\leq 0,49$, a região está em transição e se IDRS $\leq 0,099$, o desenvolvimento regional é dado como retardatário (BIANCO et 1, 2016, p. 13). 
apresentam uma dinâmica suficiente da sua base produtiva com avanços econômicos, sociais e ambientais. Uma década depois houve uma piora nos índices, pois se evidenciou a redução do número de municípios classificados em estágio avançado, passando para 0,08\% do total (BIANCO et al., 2016).

Ainda sobre o IDRS, em 2000, 97,6\% dos municípios sulistas eram classificados como retardatários, ou seja, esses municípios apresentavam dificuldades para atrair e manter recursos, de modo que seu processo de desenvolvimento socioeconômico e sustentável se tornava penoso. Em 2010, os municípios nesta situação representavam $99 \%$ do conjunto de municípios sulistas, atestando a piora do indicador para esta regiáo do país (BIANCO et al., 2016).

Outra questão que merece destaque em uma análise regional das atividades verdes é a crescente taxa de desmatamento na Amazônia Legal. A principal razão para o desmatamento dessas áreas florestais é o avanço da fronteira agropecuária, principalmente para a criaçáo de gado. A deterioração das riquezas florestais ocorre em grande parte nas regióes Norte e Centro-Oeste. Os empregos verdes no segmento de produção e manejo florestal nessas Regióes parecem insuficientes e se mostram, portanto, necessários.

Segundo o Instituto Nacional de Pesquisas Espaciais (INPE), no período de apenas um ano, entre 2014 e 2015, a área desmatada nessas regióes aumentou em 16\% (INPE, 2015). Isto tem impactos negativos sobre a geração de empregos verdes já que um dos segmentos catalogados pela OIT diz respeito a atividades de produção e manejo florestal.

Uma análise dos aspectos regionais das atividades verdes demonstra que até mesmo neste quesito o nosso país abriga um grande número de contradiçóes e desigualdades internas. É preciso considerar estas disparidades na elaboração de políticas públicas que busquem uma convergência nacional, de modo a equalizar, ou ao menos reduzir esta discrepância regional.

\section{Metodologia}

Para a realização da análise da dinâmica regional do emprego verde no Brasil foi utilizado o método shift-share ou diferencial estrutural. Esta técnica é comum na área da Economia Regional e permite analisar e comparar indicadores econômicos dentro e entre áreas de referência. $\mathrm{O}$ crescimento do emprego em uma área é decomposto em três componentes - nacional, estrutural ou setorial e regional ou competitivo - entre dois momentos do tempo. Desta forma, não é uma teoria explicativa do crescimento, mas um método que identifica os componentes deste crescimento (CAÇADOR; MONTE, 2013). $\mathrm{Na}$ literatura, alguns problemas foram levantados. $\mathrm{O}$ principal deles foi não considerar a interdependência entre os componentes, especialmente entre a composição industrial e a estrutura regional. $\mathrm{Na}$ versão reformulada, Esteban-Marquillas (1972) revisou o efeito regional para separar o componente setorial do regional, introduzindo os conceitos de emprego homotético $\left(^{*}\right)$ no Efeito Competitivo e de efeito alocação (MONTE; SILVA et al., 2013). Esta versão encontra-se detalhada na fórmula 1: 


$$
\Delta E=E N_{i j}+E S_{i j}+E C_{i j}^{*}+E A_{i j}
$$

Onde:

$$
\begin{aligned}
& \text { Efeito Nacional } E N_{i j}=E_{i j} * r_{n} \\
& \text { Efeito Setorial ou Estrutural } E S_{i j}=E_{i j} *\left(r_{i n}-r_{n}\right) \\
& \text { Efeito Competitivo ou Regional } E C_{i j}^{*}=E_{i j}^{*} *\left(r_{i j}-r_{i n}\right) \\
& \text { Efeito Alocação } E A i j=\left(E_{i j}-E_{i j}^{*}\right) * \\
& \text { Emprego Homotético } E_{i j}^{*}=\frac{E_{R j}^{0} * E_{i n}^{0}}{E_{n}}
\end{aligned}
$$

Eé o número total de empregados, $i$ o setor, $j$ a região, $n$ nacional, $r$ taxa de crescimento entre dois momentos específicos, $O$ ano inicial e $R j$ o emprego em todos os setores da regiáo. Para os propósitos desta pesquisa, o setor $i$ é representado pelas atividades que compóem o emprego verde, conforme definidas pela OIT. O efeito nacional $E N_{i j}$ representa o montante de emprego do setor $i$ na região $j$, caso este acompanhe o crescimento do emprego total da naçáo. Se, por exemplo, a variaçáo real (taxa de crescimento entre o ano inicial e final) do emprego na regiáo for inferior ao do efeito nacional, isso significa que o emprego na regiấo cresceu menos do que o emprego da naçáo no mesmo período. Além disso, ele informa as principais forças condutoras do emprego em cada regiấo: quanto maior, mais dependente é o emprego das decisōes federais. O componente setorial ou estrutural $E S_{i j}$ é dado pela diferença entre o crescimento do emprego no setor $i$ na naçáo e o emprego total na nação. Sendo positivo, a região possui uma estrutura industrial favorável e o setor na regiáo é mais dinâmico do que em nível nacional.

O efeito competitivo (ou regional) homotético $E C_{i j}^{*}$ fornece uma medida da vantagem ou desvantagem comparativa de uma regiâo em comparação com a nação no setor $i$. Ele consiste na diferença entre o crescimento do emprego no setor $i$ dentro da regiáo e o setor $i$ no país. Se o efeito competitivo for positivo, a região tem vantagens locacionais e intrínsecas ao setor. Nesta versão, o emprego homotético $E_{i j}^{*}$ é incorporado no efeito competitivo para livrá-lo da influência estrutural regional e encerrar sua interdependência com o efeito setorial. O emprego homotético $E_{i j}^{*}$ representa a magnitude que assumiria o emprego no setor $i$ na região $j$ se considerasse idêntica estrutura produtiva entre a regiáo e a nação. Junto do efeito competitivo, o efeito alocação $E A i j$ mostra se a região está se especializando em setores nos quais tem ou não uma vantagem comparativa. Quanto maior o efeito alocação, melhor é a distribuição regional do emprego entre diferentes setores.

Para testar a inclusão social, foram pesquisados e classificados os empregados conforme classificação dos rendimentos e os graus de escolaridade. Foram levantados os rendimentos por quatro níveis em unidades de salário mínimo (sm): até $1 \mathrm{sm}$, de 1 a 1,99 sm, de 2 a 4,99 sm e mais de $5 \mathrm{sm}$. Com relaçáo à escolaridade, foram pesquisadas sete 
classes: analfabetos, fundamental incompleto, fundamental completo, médio incompleto, médio completo, superior e pós-graduação.

Com relação à fonte de dados, foi utilizada a Relação Anual de Informaçôes Sociais (RAIS) disponível no site do Ministério do Trabalho (MTE). Nesta, foram pesquisados o número de empregados em 31 de dezembro de cada ano pertencentes aos seis grupos de atividades verdes descritas pela OIT, detalhadas no Anexo, e classificadas pelos códigos da Classificação Nacional de Atividades Econômicas (CNAE 2.0) do IBGE.

O período selecionado se justifica pela disponibilidade das informaçóes necessárias à realização da pesquisa: o ano de 2007 refere-se à ediçáo da CNAE 2.0 e o ano de 2015 representou o período mais recente no fornecimento dos dados de emprego.

\section{Resultados}

O emprego verde total no Brasil, conforme divulgado pelo relatório da OIT, foi cerca de 2,5 milhóes em 2008, 6,73\% do emprego nacional. Desde 2007, como pode ser observado na Tabela 1 , houve um crescimento de 30,23\% no número total de empregos verdes, no entanto, a participação no total nacional se manteve em torno de 6,6\%. Aparentemente, essa evidência sugere que o crescimento do emprego verde acompanhou o da nação como um todo.

Tabela 1 - Emprego verde no Brasil entre 2007 e 2015, total e participação no emprego total

\begin{tabular}{l|r|r|r|r|r|r|r|r|r}
\hline \multicolumn{1}{r|}{ Ano } & $\mathbf{2 0 0 7}$ & $\mathbf{2 0 0 8}$ & $\mathbf{2 0 0 9}$ & $\mathbf{2 0 1 0}$ & $\mathbf{2 0 1 1}$ & $\mathbf{2 0 1 2}$ & $\mathbf{2 0 1 3}$ & $\mathbf{2 0 1 4}$ & $\mathbf{2 0 1 5}$ \\
\hline $\begin{array}{l}\text { Empr. } \\
\begin{array}{l}\text { Verde } \\
\text { (em mil) }\end{array}\end{array}$ & 24841 & 26530 & 27196 & 29065 & 31046 & 32316 & 33024 & 33677 & 32360 \\
\hline \% do total & 6,60 & 6,73 & 6,60 & 6,59 & 6,70 & 6,80 & 6,70 & 6,70 & 6,74 \\
\hline
\end{tabular}

Fonte: Elaboração própria a partir de OIT (2009b) e MTE (2017).

Com relação aos segmentos, a partir de 2007, os destaques em termos de crescimento foram dados pelos subsetores de telecomunicaçóes, reparos e transportes, conforme a Tabela 2. A produção e o manejo florestal e a geração e distribuição de energias renováveis tiveram os piores desempenhos. Esta evidência chama a atenção para a necessidade de açóes públicas voltadas a dois principais problemas ambientais do Brasil: desmatamento e crise energética. 
Tabela 2 - Crescimento do emprego verde no Brasil por segmentos, entre 2007 e 2015 tomando 2007 como ano base

\begin{tabular}{r|r|r|r|r|r|r|r|r|r}
\hline $\begin{array}{l}\text { Segmento/ } \\
\text { ano }\end{array}$ & $\mathbf{2 0 0 7}$ & $\mathbf{2 0 0 8}$ & $\mathbf{2 0 0 9}$ & $\mathbf{2 0 1 0}$ & $\mathbf{2 0 1 1}$ & $\mathbf{2 0 1 2}$ & $\mathbf{2 0 1 3}$ & $\mathbf{2 0 1 4}$ & $\mathbf{2 0 1 5}$ \\
\hline $\mathbf{A}$ & 100 & 95,86 & 89,84 & 102,1 & 106,55 & 101 & 95,2 & 95,8 & 92,48 \\
\hline $\mathbf{B}$ & 100 & 108,28 & 111,14 & 114,7 & 121 & 120 & 117,5 & 114,5 & 110,76 \\
\hline $\mathbf{C}$ & 100 & 103,78 & 110,75 & 115 & 112,9 & 122 & 130,5 & 131,9 & 128,35 \\
\hline $\mathbf{D}$ & 100 & 107,05 & 109,9 & 112,54 & 134,05 & 141,65 & 141,37 & 144,6 & 139,45 \\
\hline $\mathbf{E}$ & 100 & 104,8 & 108,06 & 112,74 & 119,5 & 124,36 & 128,85 & 131,3 & 126,78 \\
\hline $\mathbf{F}$ & 100 & 114,97 & 116,15 & 130 & 147,94 & 160 & 169,33 & 180,7 & 174,01 \\
\hline
\end{tabular}

Fonte: Elaboração própria a partir de OIT (2009b) e MTE (2017).

Segmentos: A) Produção e manejo florestal; B) Geração e distribuição de energia renovável; C) Saneamento, gestão de resíduos e riscos ambientais; D) Manutenção, reparação e recuperação de produtos e materiais; E) Transporte coletivo e alternativo ao rodoviário e aeroviário; e F) Telecomunicaçôes e teleatendimento.

A Tabela 3 identifica a distribuição regional do emprego verde no Brasil. A Região Sudeste concentrou mais de $50 \%$ da geração desses tipos de postos de trabalho no Brasil no período. Entretanto, deve-se observar que as regióes Sudeste e Sul mostraram queda desta participação ao longo do período. Também nessas regióes, os empregos verdes alçaram crescimento aquém da esfera nacional.

Tabela 3 - Distribuição Regional do Emprego Verde no Brasil em 2007 e 2015

\begin{tabular}{l|r|r|r|r|r}
\hline \multicolumn{1}{r|}{ Regiáo/Ano } & \multicolumn{2}{|c|}{$\mathbf{2 0 0 7}$} & \multicolumn{2}{r|}{$\mathbf{2 0 1 5}$} & Variaçáo (\%) \\
\hline & total & \% do total & total & \% do total & $2007-2015$ \\
\hline Norte & 102133 & 4,11 & 148014 & 4,57 & 45,43 \\
\hline Nordeste & 396800 & 15,97 & 569661 & 17,60 & 44,15 \\
\hline Sudeste & 1417518 & 57,05 & 1790010 & 55,31 & 26,94 \\
\hline Sul & 381991 & 15,37 & 466450 & 14,41 & 22,79 \\
\hline Centro-Oeste & 186357 & 7,50 & 261952 & 8,09 & 41,10 \\
\hline Total & 2484799 & 100,00 & 3236087 & 100,00 & 30,23 \\
\hline
\end{tabular}

Fonte: Elaboração própria a partir de OIT (2009b) e MTE (2016).

Do contrário, as regióes Norte, Nordeste e Centro-Oeste ampliaram sua participação no total de empregos verdes entre os anos analisados, bem como apresentaram taxas de crescimento acima do crescimento nacional. Este é um primeiro indício de que as atividades verdes, segundo classificação da OIT, podem promover a desconcentração regional do emprego no Brasil.

Com relação aos segmentos, Tabela 4, as regióes Norte e Nordeste são as que apresentaram as maiores taxas de crescimento do setor de telecomunicaçóes, $230 \%$ e $256,1 \%$ respectivamente. O Centro-Oeste se destacou nos segmentos de energias 
renováveis, saneamento e reparação que cresceram, respectivamente, 23,7\%, 81,3\% e $88 \%$, e também foi a única região que apresentou aumento do número de contrataçóes nas atividades florestais. Deve-se notar que essas regióes são as que apresentam maior número de programas governamentais no período analisado referentes às atividades verdes, principalmente, energia renovável e saneamento.

Tabela 4 - Participação do emprego das Regióes em cada segmento (total acumulado do período) e taxa de crescimento do emprego das Regióes em cada segmento entre 2007 e 2015, em \%

\begin{tabular}{r|r|r|r|r|r|r}
\hline $\begin{array}{r}\text { Segmento/ } \\
\text { regiáo }\end{array}$ & & Norte & Nordeste & Sudeste & Sul & Centro-Oeste \\
\hline \multirow{2}{*}{$\mathbf{A}$} & Partic. & 7,78 & 16,1 & 46,4 & 21 & 8,6 \\
\cline { 2 - 7 } & Cresc. & $-16,8$ & $-19,4$ & $-1,5$ & $-15,3$ & 30,8 \\
\hline \multirow{2}{*}{$\mathbf{B}$} & Partic. & 7,8 & 19,7 & 45,9 & 12,8 & 0,021 \\
\cline { 2 - 7 } & Cresc. & 103 & 6,5 & 6,8 & $-7,8$ & 23,7 \\
\hline \multirow{2}{*}{$\mathbf{C}$} & Partic. & 4,1 & 19,6 & 55,31 & 15 & 6,26 \\
\cline { 2 - 7 } & Cresc. & 35,9 & 24,1 & 23,7 & 31,5 & 81,3 \\
\hline \multirow{2}{*}{$\mathbf{D}$} & Partic. & 3,4 & 12,9 & 55,2 & 20,05 & 8,4 \\
\cline { 2 - 7 } & Cresc. & 84,6 & 52,7 & 30,7 & 33,1 & 88 \\
\hline \multirow{2}{*}{$\mathbf{E}$} & Partic. & 5,4 & 15,9 & 58,5 & 14,6 & 5,6 \\
\cline { 2 - 7 } & Cresc. & 18 & 25,9 & 29,9 & 27,5 & 6,1 \\
\hline \multirow{2}{*}{$\mathbf{F}$} & Partic. & 0,93 & 15,7 & 68,24 & 9 & 6,1 \\
\cline { 2 - 7 } & Cresc. & 230,3 & 256,1 & 45,3 & 70,1 & 89,7 \\
\hline
\end{tabular}

Fonte: Elaboração própria a partir de OIT (2009b) e MTE (2017).

Segmentos: A) Produção e manejo florestal; B) Geração e distribuição de energia renovável; C) Saneamento, gestão de resíduos e de riscos ambientais; D) Manutenção, reparação e recuperação de produtos e materiais; E) Transportes coletivos e alternativos ao rodoviário e aeroviário e F) Telecomunicaçóes e teleatendimento.

A aplicação da metodologia shift-share permitiu investigar mais profundamente essa diferença de comportamento no crescimento do emprego verde entre as regióes do Brasil, mostrando que apesar do emprego verde no Brasil se manter em torno de 6,6\% no período, este cresceu de forma diversificada.

Os resultados da aplicação do modelo se encontram na Tabela 5. Observando o efeito nacional, verifica-se que ele foi responsável pela maior parte da variação do emprego verde na maioria das regióes, sobretudo Sul e Sudeste. Podemos interpretar, a partir dessas evidências, como sugerem Silva e Monte (2011), que os resultados do emprego verde nessas regióes são determinados principalmente por decisóes tomadas no âmbito federal.

Além disso, o componente nacional representa o montante que o emprego verde em cada região teria aumentado se tivesse crescido à mesma taxa que o emprego total do país, que foi de aproximadamente $27 \%$ no período. Se o emprego verde da região Sul tivesse crescido na mesma proporção que o emprego total nacional, em 2015 registraria um 
crescimento de 434,53\% segundo o modelo (Tabela 5), mas na realidade o emprego verde nessa região cresceu apenas $22,79 \%$ (Tabela 3).

Tabela 5 - Análise shift-share do crescimento do emprego verde nas regióes brasileiras, 2007-2015

\begin{tabular}{l|r|r|r|r|c}
\hline Regiáo / Efeitos (\%) & \multicolumn{1}{|c|}{ Nacional } & \multicolumn{1}{c|}{ Setorial } & \multicolumn{1}{c|}{ Regional } & \multicolumn{1}{c}{ Alocaçáo } & Total \\
\hline Norte & 37,91 & 23,35 & 20,030303 & 18,70 & 100 \\
\hline Nordeste & 40,08 & 22,73 & 19,2222 & 17,95 & 100 \\
\hline Sudeste & 149,25 & $-8,15$ & $-21,25$ & $-19,84$ & 100 \\
\hline Sul & 434,53 & $-88,88$ & $-127,02$ & $-118,62$ & 100 \\
\hline Centro-Oeste & 45,91 & 21,10 & 17,06 & 15,93 & 100 \\
\hline
\end{tabular}

Fonte: Elaboração própria a partir de OIT (2009b) e MTE (2017).

No entanto, a região Norte apresentou um crescimento superior ao efeito nacional, $45 \%$ contra $37,91 \%$, e a região Nordeste $44,15 \%$ contra $40,08 \%$, o que sugere que essas regiōes do país podem ter vantagens adicionais às nacionais.

De acordo com os resultados do modelo shift-share, a principal influência da variação de empregos verdes no Brasil são devido às decisões tomadas pela esfera federal. Um fator que poderia explicar o fomento destes empregos e os bons indicadores é a implantação do Programa de Aceleração do Crescimento (PAC) de 2007 a 2010, diretamente encarregado de gerar empregos, melhorar as condiçóes de vida da população em geral e reduzir as desigualdades regionais em infraestrutura. Muitas das atividades econômicas incentivadas pelo PAC estão diretamente relacionadas à geração de empregos verdes, como energia e saneamento (GOVERNO FEDERAL, 2007).

Com relação ao efeito setorial, a variação foi negativa para Sudeste e Sul, embora sejam regióes nas quais, historicamente, concentram-se as atividades econômicas do país. Um resultado negativo nesta parte do modelo indica que a região não está se especializando em setores produtivos que são mais dinâmicos em âmbito nacional.

Observa-se que, nas Regióes Norte, Nordeste e Centro-Oeste, o efeito setorial é positivo, ou seja, está havendo, nessas regióes, especialização em setores produtivos que são dinâmicos na esfera nacional, ressaltando o argumento de desconcentração regional. Estas mesmas regióes tiveram maiores taxas de crescimento do emprego em energias renováveis, saneamento, manutenção e reparos e telecomunicaçóes (Tabela 4), apesar da baixa concentração do emprego regional dessa tipologia de emprego (Tabela 3).

O efeito regional é uma medida da variação do emprego verde na região e a variação do emprego verde no Brasil (área de referência). Assim, como aponta Caçador e Monte (2013), podemos considerar que regióes com esses indicadores positivos possuem características endógenas que favorecem a atração de setores mais dinâmicos ou induzem uma expansão mais rápida em alguns setores ambientalmente amigáveis.

As regióes Norte, Nordeste e Centro-Oeste apresentam indícios de vantagem comparativa regional, o que ajuda a elucidar o porquê dessas regióes apresentarem os 
melhores resultados referentes ao mercado de trabalho sustentável. Essas vantagens podem ser ilustradas pelos resultados obtidos por essas regióes nos segmentos de energia renovável, saneamento, transportes e teleatendimento (Tabela 4).

Uma variação negativa no efeito regional indica que a regiáo apresenta desvantagem comparativa em relaçáo à área de referência. No período observado, isso ocorreu apenas com as regiốes Sudeste e Sul.

Por fim, o efeito alocação é uma medida de especialização. E pode ser entendido como um complemento do efeito setorial. Esse efeito avalia se, de fato, o país está se especializando em setores em que possui vantagem comparativa. Para um entendimento mais profundo, a Tabela 6 apresenta a decomposiçáo dessa parte do modelo.

Tabela 6 - Decomposição do Efeito Alocação

\begin{tabular}{l|r|r|r}
\hline Regióes & $\begin{array}{r}\text { Emprego homotético } \\
\text { (em postos de } \\
\text { trabalho) }\end{array}$ & $\begin{array}{r}\text { Medida de } \\
\text { especializaçáo (em } \\
\text { postos de trabalho) }\end{array}$ & $\begin{array}{r}\text { Medida de vantagem } \\
\text { comparativa (em \%) }\end{array}$ \\
\hline Norte & 6748,13 & 95384,90 & 14,68 \\
\hline Nordeste & 26217,37 & 370582,60 & 13,32 \\
\hline Sudeste & 93658,28 & 1323860,00 & $-3,95$ \\
\hline Sul & 25238,92 & 356752,10 & $-8,12$ \\
\hline Centro-Oeste & 12312,98 & 174044,00 & 10,32 \\
\hline
\end{tabular}

Fonte: Elaboração própria a partir de OIT (2009b) e MTE (2017).

O emprego homotético, segundo definiçâo oferecida por Silva e Monte (2011), é o volume de emprego em que um setor em determinada regiáo teria se a sua estrutura fosse idêntica à nacional. Trata-se de uma estimativa, uma abstração para entendermos o quanto a geração de emprego verde em determinada região está desacoplada da variação do emprego total nacional.

A terceira coluna da Tabela 6 representa o emprego verde regional menos o emprego verde regional homotético: um valor positivo indica que, na região em análise, o setor verde é especializado; um valor negativo implicaria o contrário. A quarta coluna apresenta a diferença entre a taxa de crescimento do emprego verde na região subtraída da taxa de crescimento do emprego verde no país; resultados positivos indicam que a regiáo possui vantagem comparativa em relação à esfera nacional.

A partir do exposto, conclui-se que as regióes Norte, Nordeste e Centro-Oeste apresentam vantagens comparativas em atividades econômicas verdes e no período analisado estâo se especializando nessas atividades. As regióes Sul e Sudeste estâo se especializando em atividades econômicas verdes, apesar de não serem detentoras das mesmas vantagens comparativas.

No que se refere aos rendimentos e grau de escolaridade dos empregados verdes, a Tabela 7 apresenta a distribuição regional dos empregados alocados nas atividades verdes (todos os setores da OIT), de acordo com o rendimento e níveis de escolaridade. No 
acumulado do período (2007 a 2015), a maioria das rendas verdes se concentrou na faixa de 2 a 5 salários mínimos e os salários mais elevados (acima de 5 salários), na Região Sudeste (14,93\%, valor bastante próximo da regiáo Norte).

Tabela 7 - Distribuição Regional dos empregos verdes conforme rendimento entre 2007 e $2015(\mathrm{em} \%)$

\begin{tabular}{|c|c|c|c|c|c|}
\hline & & Até $1 \mathrm{sm}$ & De 1,01a $2 \mathrm{sm}$ & De 2,01a $5 \mathrm{sm}$ & Mais de $5 \mathrm{sm}$ \\
\hline \multirow{2}{*}{ Norte } & $\%$ do total ${ }^{1}$ & 4,60 & 35,90 & 42,01 & 14,62 \\
\hline & ${\text { Tx. } \text { Cresc. }^{2}}^{2}$ & 53,49 & 40,36 & 53,20 & 25,70 \\
\hline \multirow{2}{*}{ Nordeste } & $\%$ do total ${ }^{1}$ & 11,33 & 49,60 & 26,35 & 9,70 \\
\hline & Tx. Cresc. ${ }^{2}$ & 77,15 & 47,11 & 32,96 & 16,59 \\
\hline \multirow{2}{*}{ Centro-Oeste } & $\%$ do total $^{1}$ & 4,69 & 40,37 & 38,06 & 13,64 \\
\hline & ${\text { Tx. } \text { Cresc. }^{2}}$ & 38,06 & 29,64 & 51,98 & 37,07 \\
\hline \multirow{2}{*}{ Sudeste } & $\%$ do total $^{1}$ & 4,99 & 36,82 & 38,77 & 14,93 \\
\hline & Tx. Cresc. $^{2}$ & 76,28 & 22,45 & 33,63 & 8,38 \\
\hline \multirow{2}{*}{ Sul } & $\%$ do total $^{1}$ & 4,05 & 37,78 & 40,68 & 13,51 \\
\hline & ${\text { Tx. } \text { Cresc. }^{2}}$ & 38,30 & 13,03 & 32,99 & 9,50 \\
\hline \multirow{2}{*}{ Brasil } & $\%$ do total $^{1}$ & 5,85 & 39,31 & 37,10 & 13,74 \\
\hline & ${\text { Tx. } \text { Cresc. }^{2}}^{2}$ & 68,56 & 27,26 & 35,64 & 18,30 \\
\hline
\end{tabular}

Fonte: Elaboração própria a partir de OIT (2009b) e MTE (2017).

1) Acumulado no período por nível, ou seja, soma do número de empregados em todos os anos em cada nível / acumulado total, ou seja, a soma do número de empregados em todos os anos em todos os níveis; 2) Taxa de crescimento de 2015 com relação a 2007 (2007 ano base).

Porém, as regióes Norte, Nordeste e Centro-Oeste apresentaram as maiores taxas de crescimento dos rendimentos intermediários, acima do nível nacional, de 40,36\%; $47,11 \%$ e 29,64\% respectivamente, no nível de 1 a 2 salários mínimos. Ao passo que, na faixa salarial de 2 a 5 salários mínimos, as regióes Norte e Centro-Oeste apresentaram as maiores taxas de crescimento no período analisado, superiores à nacional.

Em relação ao grau de escolaridade, a maior parcela dos empregados em atividades verdes teve ensino médio completo com destaque para a Regiáo Sudeste. No entanto, na Região Nordeste, ocorreu a maior queda da participação de analfabetos, com uma taxa de crescimento negativa de $-50,4 \%$ entre 2007 e 2015, e a regiáo Norte assistiu ao maior crescimento do ensino médio completo, de $213 \%$ no mesmo período, como pode ser observado na Tabela 8. 
Tabela 8 - Distribuição Regional dos empregos verdes conforme escolaridade entre 2007 e $2015(\mathrm{em} \%)$

\begin{tabular}{|c|c|c|c|c|c|c|c|c|}
\hline & & Analfabeto & $\begin{array}{r}\text { Fundamental } \\
\text { Incompleto }\end{array}$ & $\begin{array}{r}\text { Fundamental } \\
\text { Completo }\end{array}$ & $\begin{array}{r}\text { Médio } \\
\text { Incompleto }\end{array}$ & $\begin{array}{r}\text { Médio } \\
\text { Completo }\end{array}$ & Superior & $\begin{array}{r}\text { Pós- } \\
\text { graduaçáo }\end{array}$ \\
\hline \multirow[t]{2}{*}{ Norte } & $\%$ do total $^{1}$ & 0,53 & 22,10 & 24,70 & 8,99 & 46,38 & 6,15 & 0,95 \\
\hline & 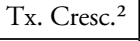 & $-33,2$ & $-23,90$ & 13,91 & 3,15 & 213,45 & 111,9 & 35,98 \\
\hline \multirow[t]{2}{*}{ Nordeste } & $\%$ do total $^{1}$ & 2,55 & 22,90 & 0,30 & 6,51 & 51,0 & 6,47 & 0,08 \\
\hline & 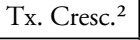 & $-50,40$ & $-32,70$ & $-11,14$ & 8,14 & 125,750 & 99,73 & 59,60 \\
\hline \multirow[t]{2}{*}{$\begin{array}{l}\text { Centro - } \\
\text { Oeste }\end{array}$} & $\%$ do total ${ }^{1}$ & 0,42 & 19,93 & 5,07 & 9,20 & 47,14 & 8,15 & 0,12 \\
\hline & Tx. Cresc. $^{2}$ & $-38,91$ & $-30,40$ & $-9,99$ & 12,48 & 66,52 & 76,32 & 185,31 \\
\hline \multirow[t]{2}{*}{ Sudeste } & $\%$ do total $^{1}$ & 0,37 & 18,38 & 0,66 & 7,01 & 52,8 & 10,42 & 0,26 \\
\hline & Tx. Cresc. $^{2}$ & $-48,20$ & $-26,81$ & $-11,00$ & 28,66 & 68,86 & 76,69 & 95,02 \\
\hline \multirow[t]{2}{*}{ Sul } & $\%$ do total $^{1}$ & 0,46 & 21,86 & 2,80 & 9,88 & 46,3 & 8,42 & 0,16 \\
\hline & Tx. Cresc. $^{2}$ & $-35,11$ & $-12,63$ & $-6,25$ & 25,82 & 103 & 84,95 & 190,36 \\
\hline \multirow[t]{2}{*}{ Brasil } & $\%$ do total ${ }^{1}$ & 0,63 & 19,83 & 2,85 & 7,88 & 50,07 & 8,58 & 0,16 \\
\hline & 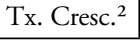 & $-47,71$ & $-25,36$ & $-9,20$ & 22,68 & 81,39 & 81,24 & 103,12 \\
\hline
\end{tabular}

Fonte: Elaboração própria a partir de OIT (2009b) e MTE (2017).

1) Acumulado no período por nível, ou seja, soma do número de empregados em todos os anos em cada nível / acumulado total, ou seja, a soma do número de empregados em todos os anos em todos os níveis; 2)Taxa de crescimento de 2015 com relaçáo a 2007 (2007 ano base).

Além disso, as regióes Norte e Nordeste tiveram as maiores taxas de crescimento em termos de ensino superior completo (111,9\% e 99,73\% respectivamente), enquanto a regiáo Centro-Oeste apresentou um aumento de 185,3\% de empregados verdes pós-graduados.

É preciso acrescentar que uma possível explicação para o bom desempenho destes indicadores sociais, pode ser atribuída às políticas públicas de valorização educacional implementadas pelo governo federal, tais como o Programa Brasil Alfabetizado (PBA), lançado pelo Ministério da Educação em 2003 com o intuito de diminuir as taxas de analfabetismo entre jovens e adultos, que permaneciam altas nas regióes economicamente periféricas de nosso país. Em 2007, o programa foi revisto para centralizar os esforços do governo federal na região Nordeste, que apresentava os piores índices de alfabetização (ME, 2017).

Assim, pode-se observar que, a partir da classificação da OIT, essas evidências indicam que no período ocorreu a desconcentração regional e melhora dos rendimentos e nível de escolaridade dos postos de trabalho verdes no Brasil.

\section{Consideraçóes finais}

O objetivo deste artigo foi aprofundar o estudo sobre empregos verdes no Brasil realizado pela OIT em 2008, a partir de uma análise da dinâmica regional e da inclusão social entre 2007 e 2015 . Verificou-se que ocorreu a manutenção da participação em torno de $6,6 \%$ e um crescimento de $30,3 \%$ do emprego verde no Brasil, mas de forma desigual 
entre as regióes. Apesar de praticamente todas as atividades verdes se concentrarem no Sudeste e Sul, as regióes Norte, Nordeste e Centro-Oeste foram as que apresentaram maiores vantagens no crescimento do emprego verde, tanto em termos setoriais como locacionais, provavelmente em decorrência das especificidades ambientais das regióes, dos segmentos de empregos verdes e impactos políticos.

A região Norte se destacou na geraçáo de postos de trabalho em fontes alternativas de energia, como hidrelétrica, biocombustível e gás. Entretanto, deve-se ressaltar sua elevada desvantagem em termos de produção e manejo florestal, ainda gritante em comparação às outras regióes e à nação. A regiẫo Centro-Oeste apresentou vantagens na área de saneamento, e a região Nordeste no setor de telecomunicaçóes e teleatendimento. Em contrapartida, os piores indicadores estiveram na região Sul, o que exige uma pesquisa específica. Além disso, as atividades verdes demonstraram elevado potencial de inclusão social, visto que, no período, houve elevadas taxas de crescimento dos maiores rendimentos (acima de 5 salários mínimos) e do nível de escolaridade (superior completo e pós-graduação) nas regiōes Norte, Nordeste e Centro-Oeste.

Essas evidências sugerem que, conforme a classificação da OIT, vem ocorrendo um avanço ou desconcentração de atividades voltadas à preservação ambiental e melhores postos de trabalho, do Sudeste em direção às regiôes menos favorecidas do Brasil. $\mathrm{Ou}$ seja, a distribuição regional do emprego verde no Brasil no período 2007-2015 indica o potencial da economia verde para promover desconcentraçáo regional e inclusão social das atividades econômicas, contribuindo para a redução das históricas desigualdades regionais do país. Algumas limitações dessa pesquisa devem ser apontadas e servir como sugestão de novas pesquisas, como: rediscutir as metodologias de medição e classificação de empregos verdes a partir de outras óticas; investigar os fatores determinantes do emprego verde, como elementos políticos ou associados às características ambientais de determinadas regióes. As interaçóes entre mercado de trabalho e meio ambiente, por fim, tende a contribuir a uma diversidade de discussóes.

\section{REFERÊNCIAS}

ANSANELLI, S. L. M.; SANTOS, L. H. B. Mercado de trabalho e meio ambiente no Brasil: a caminho do emprego verde? Economia Ensaios, v. 31, p. 231-254, 2016.

BAKKER, L. B.; YOUNG, C. E. F. Caracterizaçáo do Emprego Verde no Brasil. In: IX Encontro da Sociedade Brasileira de Economia Ecológica, Belém, PA, 2011.

BARCELLOS, F. C. A Indústria Nacional e seu potencial Poluidor. In: IV Encontro Nacional da Sociedade Brasileira de Economia Ecológica, Belém, PA, 2001.

BIANCO, T. S.; LIMA, J. F.; MOREJON, C. F.M. O indicador de desenvolvimento regional sustentável na Regiáo Sul do Brasil. Redes (Santa Cruz do Sul. Online), v.21, p. $8-28,2016$. 
CAÇADOR, S.B.; MONTE, E. Z. Crescimento do emprego no Espírito Santo: uma análise shift-share(2001-2010).Pesquisa e Debate, 2013.

EEO Review. European Employment Observatory Review. Promoting Green Jobs throughout the crisis:a handbook of best practices in Europe. União Europeia, 2013. 54 p. Disponível em: <http://www.voced.edu.au/content/ngv:58999>. Acesso em: 28 de mar. 2016.

EPE - Empresa de Energia Elétrica. EPE, 2016. Relatório Síntese. Disponível em: <http://www.cbdb.org.br/informe/img/63socios7.pdf > Acesso em: 28 de abril de 2017.

ESTEBAN-MARQUILLAS, J.M. ReinterpretationofShift-Share Analysis, 1972. Regional Science and Urban Economics, [S.1.], v. 2, n. 3, p.249-255.

FERRERA DE LIMA, J.; ALVES, L. R.; EBERHARDT, P.H.C.; DEL BIANCO, T. S.. Mensurar as Desigualdades Regionais no Brasil: Proposta Metodológica. In: V Seminário Internacional de Desenvolvimento Regional, 2011, Santa Cruz do Sul. Anais... do V SIDR 2011. Santa Cruz do Sul: UNISC, vol. 01, p. 180-195, 2011.

GUALDA, N. L. P.. IDR - Proposta Metodológica. Texto para Discussáo. Programa de Mestrado em Economia - PME. Universidade Estadual de Maringá, 1995.

GUALDA, N. L. O Índice de Desenvolvimento Regional como fator de identificação de polos de crescimento regionais - uma tentativa de identificação para a economia paranaense. In: II Encontro de Economia Paranaense, 2003, Maringá. Anais... Maringá: TAC - Multimídia, p. 566- 583, 2003.

GOVERNO FEDERAL, 2007. Programa de Aceleração do Crescimento 2007-2010. Apresentação de Power Point. Disponível em: <http://www.fazenda.gov.br/centrais-deconteudos/apresentacoes/2007/r220107-pac-pdf29>. Acesso em: 01 de mai. de 2017.

IBGE - INSTITUTO BRASILEIRO DE GEOGRAFIA E ESTATÍSTICA, 2016. Disponível em: <http://ibge.gov.br>. Acesso em: 02 de mai. de 2017.

INPE - INSTITUTO NACIONAL DE PESQUISAS ESPACIAIS, 2015. Divulgação do PRODES 2015. Disponível em: <http://www.obt.inpe.br/prodes/Prodes_Taxa2015_ estimativa.pdf>. Acesso em: 01 de mai. de 2017.

INSTITUTOTRATABRASIL, 2015. Disponível em: <http://www.tratabrasil.org.br/ saneamento-no-brasil>. Acesso em: 02 de mai. de 2017.

KON, A.; SUGAHARA, C. Sustentabilidade e empregos verdes no Brasil. Curitiba: Editora APPRIS, 2012.

MAZZUCATO, M. O Estado Empreendedor: desmascarando o mito do setor público vs. setor privado.São Paulo: Editora Portfolio-Penguin, 2014. 304 p. 
ME. MINISTÉRIO DA EDUCAÇÃO. Programa Brasil Alfabetizado, 2017. Disponível em <http://portal.mec.gov.br/programa-brasil-alfabetizado $>$. Acesso em: 01de mai. de 2017.

MTE. MINISTÉRIO DO TRABALHO E DO EMPREGO, 2016. Disponível em <http://www.mte.gov.br>. Acesso em: 01 de mai. de 2017.

MONTE, P. A.; SILVA, J. A. R.; GONÇALVES, M. F. 2013. A Dinâmica do Emprego na Região Nordeste no Período 2000 a 2009. Revista Econômica do Nordeste, v.44, n.1, p. 9-26.

OCDE - Organização para Cooperação e Desenvolvimento Econômico. A Caminho do Crescimento Verde: Um Sumário para os Decisores Políticos. Paris, 2011. Disponível em: <https:/www.oecd.org/greengrowth/48536946.pdf>. Acesso em: 02 de mai. de 2017.

OIT - Organização Internacional do Trabalho Escritório no Brasil. OIT. 2008. Empregos Verdes: Trabalho decente em um mundo sustentável e com baixas emissóes de carbono.

OIT - Organização Internacional do Trabalho Escritório no Brasil. Programa Empregos Verdes OIT. 2009a.

OIT - Organização Internacional do Trabalho Escritório no Brasil. Empregos Verdes no Brasil: quantos são, onde estão e como evoluirão nos próximos anos. $2009 \mathrm{~b}$.

RODRIGUES, K.F., FERRERA DE LIMA, J. Índice de desenvolvimento regional sustentável: uma análise das mesorregióes do Estado do Paraná no período de 2002 a 2008. Revista Geografar, Curitiba (PR), vol.8, no1, p.175-202, 2013.

SILVA, J. A. R.; MONTE, P. A. Dinâmica regional e setorial do emprego no Brasil: 1997 a 2007. Revista de Economia, v. 37, n. 2 (ano 35), p. 80-108, mai./ago. 2011.

TOLMASQUIM, M. T., Energia Renovável: hidráulica, biomassa, eólica, solar e oceânica. Empresa de Pesquisa em energia. 2016. Disponível em <http://www.epe.gov. br/Documents/Energia\%20Renov\%C3\%A1vel\%20-\%20Online\%2016maio2016.pdf>. Acesso em: 02de abr. de 2017.

United Nations Environment Programme. UNEP. 2008. Background Paper on Green Jobs.

UNEP. United Nations Environment Programme. Towards a green economy, pathways to sustainable development and poverty erradication. 2011. Disponível em: <http:// www.ipu.org/splz-e/rio+20/rpt-unep.pdf>. Acesso em: 02 de abr. de 2017.

YOUNG, C. E. F. Potencial de crescimento da economia verde no Brasil. Política Ambiental, Belo Horizonte, v.8, p. 88-97, 2011. 


\section{ANEXO- Atividades Verdes}

\begin{tabular}{|c|c|}
\hline $\begin{array}{l}\text { CNAE } \\
2.0\end{array}$ & Descrição \\
\hline$A$ & Produção e manejo florestal \\
\hline $0142-3$ & Produção de mudas e outras formas de propagação vegetal \\
\hline 0210-1 & Produção florestal-florestas plantadas \\
\hline $0220-9$ & Produçáo florestal-florestas nativas \\
\hline $0230-6$ & Atividades de apoio à produção florestal \\
\hline $8130-3$ & Atividades paisagísticas \\
\hline $9103-1$ & $\begin{array}{l}\text { Atividades de jardins botânicos, zoológicos, parques nacionais, reservas ecológicas } \\
\text { e áreas de proteçáo ambiental }\end{array}$ \\
\hline$B$ & Geração e distribuição de energias renováveis \\
\hline 0113-0 & Cultivo de cana de açúcar \\
\hline $1931-4$ & Fabricação de álcool \\
\hline $1932-2$ & Fabricação de biocombustíveis, exceto álcool \\
\hline $3511-5$ & Geraçáo de energia elétrica \\
\hline $3512-3$ & Transmissão de energia elétrica \\
\hline $3513-1$ & Comércio atacadista de energia elétrica \\
\hline $3514-0$ & Distribuição de energia elétrica \\
\hline $3520-4$ & $\begin{array}{l}\text { Produção de gás; processamento de gás natural; distribuição de combustíveis } \\
\text { gasosos por redes urbanas }\end{array}$ \\
\hline $4221-9$ & Obras para geração e distribuição de energia elétrica \\
\hline$C$ & Saneamento, gestão de resíduos e de riscos ambientais \\
\hline $2825-9$ & Fabricação de máquinas e equipamentos para saneamento básico e ambiental \\
\hline $3600-6$ & Captação, tratamento e distribuição de água \\
\hline $3701-1$ & Gestão de redes de esgoto \\
\hline $3702-9$ & Atividades relacionadas a esgoto, exceto a gestão de redes \\
\hline $3811-4$ & Coleta de resíduos não perigosos \\
\hline $3812-2$ & Coleta de resíduos perigosos \\
\hline $3821-1$ & Tratamento e disposição de resíduos não perigosos \\
\hline $3822-0$ & Tratamento e disposição de resíduos perigosos \\
\hline $3900-5$ & Descontaminação e outros serviços de gestão de resíduos \\
\hline $4222-7$ & $\begin{array}{l}\text { Construçáo de redes de abastecimento de água, coleta de esgoto e construçóes } \\
\text { correlatas }\end{array}$ \\
\hline $8425-6$ & Defesa Civil \\
\hline$D$ & Manutenção, reparação e recuperação de produtos e materiais \\
\hline $2212-9$ & Reforma de pneumáticos usados \\
\hline $2950-6$ & Recondicionamento e recuperação de motores para veículos \\
\hline
\end{tabular}




\begin{tabular}{|c|c|}
\hline $\begin{array}{l}\text { CNAE } \\
2.0\end{array}$ & Descrição \\
\hline $3311-2$ & $\begin{array}{l}\text { Manutenção e reparação de tanques, reservatórios metálicos e caldeiras, exceto para } \\
\text { veículos }\end{array}$ \\
\hline $3312-1$ & Manutenção e reparação de equipamentos eletrônicos \\
\hline $3313-9$ & Manutenção e reparação de máquinas e equip. elétricos \\
\hline $3314-7$ & Manutenção e reparação de máq. e equip. da ind. mecânica \\
\hline $3315-5$ & Manutenção e reparação de veículos ferroviários \\
\hline $3316-3$ & Manutenção e reparação de aeronaves \\
\hline $3317-1$ & Manutenção e reparação de embarcações \\
\hline $3319-8$ & $\begin{array}{l}\text { Manutenção e reparação de equipamentos e produtos não especificados } \\
\text { anteriormente }\end{array}$ \\
\hline $3831-9$ & Recuperação de materiais metálicos \\
\hline $3832-7$ & Recuperação de materiais plásticos \\
\hline $3839-4$ & Recuperação de materiais não especificados anteriormente \\
\hline $4520-0$ & Manutenção e reparação de veículos automotores \\
\hline $4543-9$ & Manutenção e reparação de motocicletas \\
\hline $4687-7$ & Comércio atacadista de resíduos e sucatas \\
\hline $4785-7$ & Comércio varejista de artigos usados \\
\hline $9511-8$ & Reparação e manutenção de computadores e de equip. perif. \\
\hline $9512-6$ & Reparação e manutenção de equipamentos de comunicação \\
\hline $9521-5$ & $\begin{array}{l}\text { Reparação e manutenção de equipamentos eletroeletrônicos de uso pessoal e } \\
\text { doméstico }\end{array}$ \\
\hline $9529-1$ & $\begin{array}{l}\text { Reparação e manutenção de objetos e equipamentos pessoais e domésticos não } \\
\text { especificados anteriormente }\end{array}$ \\
\hline E & Transportes coletivos e alternativos ao rodoviário e aeroviário \\
\hline $3011-3$ & Construção de embarcações e estruturas flutuantes \\
\hline $3031-8$ & Fabricação de locomotivas, vagóes e outros materiais rodantes \\
\hline $3032-6$ & Fabricação de peças e acessórios para veículos ferroviários \\
\hline $3092-0$ & Fabricação de bicicletas e triciclos não motorizados \\
\hline $4223-5$ & Construção de redes de transportes por dutos, exceto para água e esgoto \\
\hline $4291-0$ & Obras portuárias, marítimas e fluviais \\
\hline $4911-6$ & Transporte ferroviário de carga \\
\hline $4912-4$ & Transporte metroferroviário de passageiros \\
\hline $4921-3$ & $\begin{array}{l}\text { Transporte rodoviário coletivo de passageiros, com itinerário fixo, municipal e em } \\
\text { regiâo metropolitana }\end{array}$ \\
\hline $4922-1$ & $\begin{array}{l}\text { Transporte rodoviário coletivo de passageiros, com itinerário fixo, intermunicipal, } \\
\text { interestadual e internacional }\end{array}$ \\
\hline 4924-8 & Transporte escolar \\
\hline
\end{tabular}




\begin{tabular}{|l|l|}
\hline CNAE & Descrição \\
\hline $4929-9$ & $\begin{array}{l}\text { Transporte rodoviário coletivo de passageiros, sob regime de fretamento, e outros } \\
\text { transportes rodoviários náo especificados anteriormente }\end{array}$ \\
\hline $4940-0$ & Transporte dutoviário \\
\hline $5011-4$ & Transporte marítimo de cabotagem \\
\hline $5012-2$ & Transporte marítimo de longo curso \\
\hline $5021-1$ & Transporte por navegação interior de carga \\
\hline $5022-0$ & Transporte por navegação interior de passageiros em linhas regulares \\
\hline $5030-1$ & Navegação de apoio \\
\hline $5091-2$ & Transporte por navegação de travessia \\
\hline $5099-0$ & Transportes aquaviários não especificados anteriormente \\
\hline $5222-2$ & Terminais rodoviários e ferroviários \\
\hline $5231-1$ & Gestão de portos e terminais \\
\hline $5232-0$ & Atividades de agenciamento marítimo \\
\hline $5239-7$ & Atividades auxiliares dos transportes aquaviários não especific. anteriorm. \\
\hline$F$ & Telecomunicaçóes e tele-atendimento \\
\hline $6110-8$ & Telecomunicaçôes por fio \\
\hline $6120-5$ & Telecomunicaçóes sem fio \\
\hline $6130-2$ & Telecomunicações por satélite \\
\hline $6190-6$ & Outras atividades de telecomunicaçóes \\
\hline $8220-2$ & Atividades de teleatendimento \\
\hline
\end{tabular}

Fonte: OIT (2009b). 